\title{
Malnutrition Trends in School Children of Madinah Al Munawarrah-A Cross-Sectional study
}

\section{Atta UR Rehman Khan* and Meshal Al Malki}

Prince Muhammad Bin Abdulaziz Hospital, Madinah Al Munawarrah, King Abdullah International Medical Research Centre (KAIMRC), Riyadh and King Saudi Bin

Abdulaziz University for Health Sciences (KSAU-HS), Riyadh and Ministry of National

Guard Health Affairs, Saudi Arabia

*Corresponding Author: Atta UR Rehman Khan, Prince Muhammad Bin Abdulaziz

Hospital, Madinah Al Munawarrah, King Abdullah International Medical Research

Centre (KAIMRC), Riyadh and King Saudi Bin Abdulaziz University for Health

Sciences (KSAU-HS), Riyadh and Ministry of National Guard Health Affairs, Saudi

Arabia.
Received: June 23, 2020

Published: September 30, 2020

(C) All rights are reserved by Atta UR Rehman

Khan and Meshal Al Malki.

\section{Abstract}

Background: Malnutrition is considered a major challenge in the area of public health nutrition. But recently the clear footprints have been spotted by researchers at remarkable magnitude even in the developing as well as developed countries. National studies to predict Malnutrition prevalence in Saudi Arabia are lacking. To date no study has been conducted to find out prevalence of Malnutrition in the $2^{\text {nd }}$ holiest city of Muslims Al Madinah Al Munawarrah located on western part of Saudi Arabia.

Objectives: This study aimed to evaluate the prevalence of Malnutrition in school children of Madinah Al Munawarrah-Saudi Arabia. Methods: Participants were healthy school boys and girls aged 05 - 18 years. It was a cross-sectional stratified study. Total sample size was 6000 consisting of 3000 boys and 3000 girls Twenty (20) schools were selected with random stratification with the help of Ministry of education. Data were collected during April - December 2017. Height and weight of children were measured to calculate percentiles for BMI-for-age and -sex according to the 2000 Centers for Disease Control and Prevention (CDC) growth charts. Acute Malnutrition was defined as BMI-for-age $/ \mathrm{sex}<5^{\text {th }} \%$ tile.

Results:

Acute malnutrition: The overall children who were suffering from Acute Malnutrition were $19 \%(\mathrm{n}=755)$. Prevalence in boys was $24 \%(n=529)$ and in girls was $13 \%(n=226)$.

For boys: The presence of Acute Malnutrition in Category-I ( 5 - 8 years) was 25\% ( $\mathrm{n}=8)$, category-II $(9-13$ years) was $23 \%(\mathrm{n}=$ 149) and Category-III (14 - 18 years) was $24 \%(n=372)$.

For girls: The prevalence in Category-I ( 5 - 8 years) was $41 \%(\mathrm{n}=45)$, category-II $(9-13$ years) was $13 \%(\mathrm{n}=79)$ and Category-III (14 - 18 years) was $10 \%(n=102)$.

Conclusion: Malnutrition in school children in Al Madinah Al Munawarrah prevails as high as in few under developed countries. Integrated Intervention and prevention programs in primary through high school should focus at all school-aged children especially primary school students. Ministry of education and Ministry of health have a key role. Dietitians and public health nutrition care workers are potential key role players to effectively address this issue.

Keywords: Malnutrition; Obesity; Climate; Saudi Arabia 


\section{Introduction}

Undernutrition is one of the three pandemics beside obesity and climate change which is now an emerging threat to health and survival of human [1]. Nutrition optimization is a must for both mental and physical health of our children. Kids who are well nourished are healthy, productive and able to learn. Healthful nutrition brings benefits to individuals, families, communities and the world at large. Under nutrition is, by the same logic, devastating. It blunts the intellect, saps the productivity of everyone it touches and perpetuates poverty. Adequate nutritional intake gives every child the best start in life. Undernutrition contributes to nearly $45 \%$ of all deaths in children under 5 years old globally [2]. Low and middle income countries are worst affected [3]. Treatment services are estimated to reach less than $15 \%$ of undernourished children [4].

Malnutrition in all its forms is the highest risk factor for compromised health and premature mortalities globally [5]. Type of malnutrition differs by stage of development. The Prevalence of malnutrition (undernutrition) in female student from 5-19 years in Saudi Arabia is $13 \%$ which is similar to high income Asia pacific and southern Latin American countries. Whereas Central Asia 14\%, Central Europe 15\%, Eastern Europe 16\%, Southern Africa $17 \%$, Caribbean 17\%, Middle east 18\% [1]. The nutritional status of school-aged children influences the health, cognitive skills, and ultimately the educational performance. The school is an opportune setting to provide health and nutrition services to disadvantaged children. Yet, school-aged children are not commonly included in health and nutrition surveys. An up-to-date overview of their nutritional status across the world is not available. The available data indicate that malnutrition is a public health issue in schoolaged children in developing countries and countries in transition.

Despite the increased prevalence of nutritional disorders in the kingdom, one hardly finds any regular National Nutrition survey such as National Health and Nutrition Examination survey (NHANES) in USA. Therefore, one does not find a consistent children health and Nutrition data base. This creates a big gap to formulate policy on prevention of nutritional disorders and associated comorbidities in the kingdom. Many small nutrition surveys and studies have been done in eastern, central and southern region but no study was carried out in western region and the Holy city of Al Madinah Al Munawarrah until to date. To fill in the wide information gap in nutritional status of school children, this study was designed with the aim to investigate prevalence of malnutrition in school-going children in the $2^{\text {nd }}$ Muslim holiest city of Madinah Al Munawarrah. We now report our study methods and results.

\section{Objectives of the Study}

Objectives of the study was to find out Malnutrition such as under nutrition in school children in Al MADINAH Al Munawarrah.

- $\quad$ To study the prevalence of undernutrition in school-aged students.

- $\quad$ To evaluate the dietary habits.

\section{Methods}

\section{Study design}

It was a Cross-sectional Study. A pre structured self-administered questionnaire was used to collect the data on demographics, anthropometrics, dietary and physical lifestyle of the children. An informed consent was filled either by parent or guardian or school administration. Dietary intake was recorded by Food Frequency Questionnaire (FFQ) which will be published elsewhere.

\section{Setting}

Government schools in Madinah Research staff from Prince Muhammad Bin Abdulaziz Hospital -National Guard Health Affairs, Clinical Nutrition department carried out data collection, entry and analysis in the $2^{\text {nd }}$ Holy Most city in the Muslim world $\mathrm{Al}$ Madinah $\mathrm{Al}$ Munawarrah west of Kingdom of Saudi Arabia. Ministry of Education in Madinah Al Munawarrah collaborated in completion of the project. The data collection was done between April - December 2017.

\section{Ethical approval}

The study was approved by Institutional review Board of King Abdullah International Medical Research Centre and King Saud Bin Abdulaziz university, Ministry of National Guard Health Affairs. No conflict of interest to disclose.

\section{Sampling technique, inclusion and exclusion criteria}

Sampling was done by random selection of schools and classes. Whereby all city schools in Madinah were stratified based on areas into four strata based on directions (East, West, North and South). An estimated population of the school children in Madinah is in the range of 50 - 60 thousands in all 100 plus schools. Probability stratified sampling was done to reach to a size of 6000 students with confidence Interval of $95 \%$. 
Approximately $50 \%$ boys and $50 \%$ girls. This was around 10 $15 \%$ of the total students in Madinah city. Inclusion Criteria was the healthy school boys and girls aged 05 - 18 years whereas any student with diagnosed medical problem such as Diabetes Mellitus Type I was excluded. Sampling was done with random stratification of schools and then random selection of classes in stratified schools. Total sample size was 6000, which further divided into 3000 boys and 3000 girls (10\% of overall population of school students). Twenty (20) schools were selected randomly out of total 110 schools with the help of Ministry of education.

\section{Outcome measures}

Primary measures was Body Mass Index and which was calculated as $\mathrm{Kg} / \mathrm{m}^{2}$, which was also used as a measure of obesity because it correlates well with adiposity [6]. Anthropological measures of weight and height were taken following the interview. All subjects were measured when they were barefoot, and wear only light clothes. Weight was measured by standardized calibrated scales to the nearest $0.1 \mathrm{~kg}$ and height was taken to the nearest $0.1 \mathrm{~cm}$ using the standardized wall-mounted height boards with a sliding head piece. Children's height and weight were used to calculate percentiles for BMI-for-age and -sex according to the 2000 Centers for Disease Control and Prevention (CDC) growth charts, acute malnutrition was defined as BMI-for-age $<5^{\text {th }}$ percentile of the 2000 sex-specific CDC growth charts $[7,8]$.

Secondary outcome measure was nutritional intake that was analysed by considering of portion frequencies per day, week and month.

\section{Statistical analysis}

Data was coded and analyzed using JMP- SAS Statistical Package. Descriptive statistics was used to determine mean and standard deviations for Age, Weight, Height and Body Mass Index of all sample and sub-groups based on age categories. Frequencies were calculated for students who were acutely malnourished. All the analysis was done as first combined and then separately for male and female students.

\section{Results}

A total number of 3987 school children responded on self-administered questionnaire which was initially distributed to 6000 children. 3000 were girls and 3000 were boys. The response rate was recorded as 67\%. Out of total 3987 children, 2222 (56\%) were boys and 1765 (44\%) were girls who responded with fully or par- tially filled questionnaire. All above means and standard deviations are in the table 1.

The demographics showed that the overall mean age for the whole sample was 14 years ( $\mathrm{SD} \pm 2.54$ ). Mean age for boys was 14.4 years ( $\mathrm{SD} \pm 2.27$ ) and girls was 13.88 years ( $\mathrm{SD} \pm 2.81$ ). The overall mean age (both boys and girls included) in Category- I ( 5 - 8 years) was 7.71 (SD \pm 0.63 ), category-II ( 9 - 13 years) was 11.82 (SD \pm 1.31 ) and Category-III (14 - 18 years) was 15.68 (SD \pm 1.35 ). The overall mean weight was 50.3 ( $S D \pm 17.6)$. Mean weight for boys was 52.53 (SD \pm 18.26 ) kg. Mean weight for girls was 47.54 (SD $\pm 16.48) \mathrm{kg}$. In boys the mean weight in Category- I ( 5 - 8 years) was 26.05 (SD \pm 6.08 ), category-II ( 9 - 13 years) was 40.7 (SD \pm 13.2) and Category-III (14 - 18 years) was 57.9 (SD \pm 17.45$)$. In girls the mean weight in Category- I ( 5 - 8 years) was 22.9 (SD \pm 5.7 ), category-II ( 9 - 13 years) was 42.08 (SD \pm 14.08 ) and CategoryIII (14 - 18 years) was 53.46 (SD \pm 14.99 ). The overall height was 1.54 ( $\mathrm{SD} \pm 0.12$ ) meters. Mean height for boys was 1.57 (SD \pm 0.13 ) meters. Mean height for girls was 1.50 ( $\mathrm{SD} \pm 0.11$ ) meters. For boys the mean height in Category- I ( 5 - 8 years) was 1.26 (SD \pm 0.04 ), category-II ( 9 - 13 years) was 1.45 (SD \pm 0.09 ) and Category-III (14 - 18 years) was 1.63 (SD \pm 0.09 ). For girls the mean height in Category- I ( 5 - 8 years) was 1.23 ( $S D \pm 0.06$ ), category-II ( 9 - 13 years) was 1.46 (SD \pm 0.10$)$ and Category-III (14 - 18 years) was 1.55 (SD \pm 0.06 ) (Table 1).

Body mass index (2000 centre for disease control - CDC reference) [7]

The overall mean Body Mass Index (BMI) was 20.7 (SD \pm 5.84 ) $\mathrm{KG} / \mathrm{M}^{2}$. Mean Body Mass Index (BMI) for boys was 20.78 (SD \pm 6.03 ) $\mathrm{KG} / \mathrm{M}^{2}$ and mean Body Mass Index (BMI) for girls was 20.64 (SD \pm 5.5) $\mathrm{KG} / \mathrm{M}^{2}$. In boys the mean BMI in Category- I (5 - 8 years) was 16.08 (SD \pm 2.75 ), category-II ( 9 - 13 years) was 18.95 (SD \pm 4.56 ) and Category-III (14 - 18 years) was 21.62 (SD \pm 6.38 ). For girls the mean BMI in Category- I (5 - 8 years) was 14.94 (SD \pm 2.59 ), category-II ( 9 - 13 years) was 19.25 (SD \pm 4.86 ) and Category-III (14 - 18 years) was 22.10 (SD \pm 5.65 ). All above means and standard deviations are in the table 1.

\section{Prevalence of malnutrition (BMI $<5^{\text {th }}$ Percentile)}

\section{Acute malnutrition}

The overall children who were suffering from acute malnutrition were $19 \%(n=755)$. Prevalence in boys was $24 \%(n=529)$ and in girls was $13 \%(\mathrm{n}=226)$. 


\begin{tabular}{|l|c|c|} 
Variables & Numbers(N) & Percentage (\%) \\
\hline Gender (\%) & \multicolumn{2}{|l|}{} \\
\hline Male & 2222 & 55.7 \\
\hline Female & 1765 & 44.3 \\
\hline Age Category & Male: Female & Male: Female \\
\hline 5-8 & $32: 110$ & $1: 6$ \\
\hline 9-13 & $636: 624$ & $29: 35$ \\
\hline $14-18$ & $1554: 1031$ & $70: 58$ \\
\hline
\end{tabular}

Table 1: School Children Demographics in the Holy city of Madinah Al Munawarah.

- For boys: The presence of Acute Malnutrition in Category- I (5 - 8 years) was $25 \%(n=8)$, category-II ( 9 - 13 years) was $23 \%$ $(\mathrm{n}=149)$ and Category-III (14 - 18 years) was $24 \%(\mathrm{n}=372)$.

- For girls: The prevalence in Category- I (5 - 8 years) was $41 \%$ $(\mathrm{n}=45)$, category-II ( 9 - 13 years) was $13 \%(\mathrm{n}=79)$ and Category-III (14 - 18 years) was $10 \%(n=102)$.

All information on nutrition status are in the table 2.

\begin{tabular}{|l|c|c|}
\hline Nutritional status (NS) & Numbers (N) & Percentage (\%) \\
\hline Acute Malnutrition (0) & 755 & $19 \%$ \\
\hline Normal (1) & 2026 & $51 \%$ \\
\hline Overweight (2) & 616 & $15.4 \%$ \\
\hline Obese (3) & 588 & $14.7 \%$ \\
\hline
\end{tabular}

Table 2: Overall nutritional status in the holy city of Madinah $\mathrm{Al}$ Munawarah.

\begin{tabular}{|l|c|c|c|c|c|}
\hline \multirow{2}{*}{ Foods } & \multirow{2}{*}{ Frequency } & \multicolumn{2}{|c|}{ Numbers } & \multicolumn{2}{c|}{$\begin{array}{c}\text { Percentages } \\
\text { (\%) }\end{array}$} \\
\cline { 3 - 6 } & & Male & $\begin{array}{c}\text { Fe- } \\
\text { male }\end{array}$ & Male & $\begin{array}{c}\text { Fe- } \\
\text { male }\end{array}$ \\
\hline Soft Drinks & Daily & 814 & 393 & $37 \%$ & $24 \%$ \\
\hline Chocolates & Daily & 550 & 719 & $25 \%$ & $42 \%$ \\
\hline Hot Chocolate & Daily & 175 & 180 & $8 \%$ & $11 \%$ \\
\hline Pizza & Daily & 159 & 179 & $7 \%$ & $10 \%$ \\
\hline $\begin{array}{l}\text { Fried Foods at } \\
\text { Home }\end{array}$ & Daily & 1950 & 1596 & $88 \%$ & $91 \%$ \\
\hline Coffee or Tea & Daily & 1122 & 687 & $52 \%$ & $42 \%$ \\
\hline Candies & Daily & 401 & 432 & $19 \%$ & $26 \%$ \\
\hline French Fries & Daily & 427 & 389 & $19 \%$ & $24 \%$ \\
\hline Spaghetti or Past & Daily & 261 & 320 & $12 \%$ & $19 \%$ \\
\hline Fats and Butter & Daily & 212 & 136 & $10 \%$ & $7 \%$ \\
\hline $\begin{array}{l}\text { Frequency of } \\
\text { Fried Foods }\end{array}$ & Daily & 664 & 474 & 30 & 28 \\
\hline $\begin{array}{l}\text { Type of Fat to fry } \\
\text { at home }\end{array}$ & $\begin{array}{c}\text { Daily (But- } \\
\text { ter and }\end{array}$ & 106 & 818 & 50 & 53 \\
\hline
\end{tabular}

Table 3: Frequently highly consumed foods in school children in the holy city of Madinah Al Munawarah.

\section{Discussion}

Undernutrition is both a medical and social disorder [9]. It may be caused by inadequate dietary intake or infection or disease that affects the child. Poor sanitation and hygiene, lack of adequate care, weak economic and food insecurity are contributory factors. Social, cultural, political, and legal factors that influence availability and use of resources further contribute to child undernutrition [10].

On the other hand the alarming findings were recorded by our study on the incidence of Acute Malnutrition which was used to be considered as nutritional deficiency of poorer regions such as Africa and some part of Asia such as India, Pakistan and Bangladesh. It was revealed in our findings that the Acute Malnutrition incidence has similar pattern as found in poverty stricken countries. The prevalence was as high as overall $19 \%$ and based on gender, it was prevalent in $24 \%$ male and $13 \%$ in female students. The highest presence was recorded in our data amongst category -1 (5 - 8 year) in both male and female students. Prevalence of Acute Malnutrition in this category was $41 \%$ in female students and $25 \%$ in male students. Female students showed highest tendency of childhood malnutrition. This is an important revelation as such prevalence was never reported in the kingdom in any study before. This has a critical aspect of delayed mental and physical development in school children and ultimately resulting into poor school performance. Malnutrition has negative effects on the cognitive development of children. It also blunts the physical growth such as height and weight of the school going children.

\section{Low intake of healthy foods (Table 3)}

We found a lower consumption of healthy foods as milk, fruits, vegetables. Milk intake was significantly less than recommended intake as only $37 \%$ of boys and $32 \%$ of girls in our study consumed on daily basis. We also found that the beans which are in fiber and protein are consumed daily by $6 \%$ boys and $4 \%$ girls consumed. The same pattern of inadequate intake of fruits, vegetables group was recorded. This causes deficiencies of important nutrients from daily diet. It might lead to micronutrient deficiencies as well such as Vitamins, mineral and other crucial trace elements which play critical role in the metabolism, immune system enhancement and mental development. The adverse clinical consequence may be in the more infectious and metabolic diseases.

\section{High intake of junk and fast foods (Table 3)}

In this study the consumption of soft drinks was found $37 \%$ in males and $24 \%$ in females on daily basis. Drinking 4 - 5 servings of these drinks was also noted in quite large numbers. Same way consumption of chocolates, coffee/tea was highest in female students with $42 \%$ and fried foods at $91 \%$. Whereas boys were high consumers of fried foods (88\%) and coffee/tea (52\%). Females are also high consumer of Candies (26\%) and french fries (24\%). Use of 
butter and margarine with high content of saturated fats is highly prevalent in both male and female students. Eating food with low nutritional value and snacks while watching TV may be linked to obesity. For instance, Musaiger documented the Chocolates, potato chips, nuts, and soft drinks are the most common food consumed while viewing TV among school children. Moreover, TV is the most widely used media for advertising which has a big effect on eating habits especially for children in the Arab Gulf Countries [11].

Eating out has been highly prevalent in the Co-operation Council of the Arab States of the Gulf (GCC) states (United Arab Emirates, Bahrain, Saudi Arabia, Oman, Qatar and Kuwait) as well as in other predominantly middle-income countries particularly in urban areas. However, studies related to obesity with eating out in GCC are limited. For example, in SA the proportion of obesity is expected to reach more than $52 \%$ among children who eat outside the home for five times per week or more (10). US people spend about half of their food budget on food prepared outside of the home and nearly one-third of their daily calories come from these sources, In addition, parents of families who ate at restaurants weekly or greater reported that their children consumed more sugar-sweetened beverages, more sweet/savory snacks, and less water compared with families who do not frequent restaurants (11) [12].

Lethal home environment and sick school canteens

In our study, the consumption of junk and fast foods is too high because home environment and school environment is detrimental with regards to healthy food choices Parents at home lack in education on health and nutrition find themselves incapable to guide their children on healthy food choices and on the other hand the rest of the damage is done by school canteens as they are selling all junk foods through out the city. Most students reported consumption of junk foods by school canteens. Such as chocolates, candies, soft drinks, pizza and french fries consumption was significantly high. Junk food culture was a common dietary practice amongst boys and girls.

\section{Study Strengths}

As far as strengths are concerned, this is the first time we have laid the foundation of scientific health data base of children with present results on health status of our children in the $2^{\text {nd }}$ holiest city of Muslims after Makkah in the whole world. This will be a baseline data for future researches to start with other health objec- tives in children of this holy city. This can also act as health quality improvement benchmark as well as a first ever available reference standard. These results can be instrumental to gauge the future changes in prevalence of undernutrition at local level.

\section{Study Limitations}

We have got few limitations to share in our study. First, the response rate of completion of questionnaire with food frequencies and anthropometrics was $66 \%$. This is slightly higher than expected. The $34 \%$ non-responsiveness in our study data might create a sample bias and ultimately in prevalence results in both directions. Secondly, we used the CDC 2000 reference standard for BMI which underestimates the prevalence when compared with WHO standards 2007. This might make it difficult to compare with studies done by using IOTF or WHO cut offs.

\section{Future Research Ideas}

Due to the large sample size and unavailability of Nutritional analysis software we could not map complete nutritional profile of macro nutrients and micronutrients. In future studies strongly recommended to include this data. Moreover, Saudi Arabia needs to establish a national governmental database about malnutrition in school children through national health Examination survey such as conducted in the US.

\section{Recommendations}

- Regular School Nutrition surveys every 5 years.

- Launch Diet and Nutrition awareness programs in all schools through Ministry of Education (MOE) in collaboration with Prince Muhammad Bin Abdulaziz Hospital research and Clinical staff and other nutrition healthcare professional bodies

- $\quad$ Systematic and orderly follow up to evaluate the effects of the program on Body Mass Index (BMI) results, weight and Nutrition related knowledge, attitudes, and behaviors of children.

- Develop a Nutritional data base throughout MADINAH Schools.

- $\quad$ Revise and monitor school canteen menu.

- Design and Implement BMI Measurement Program in all schools. 


\section{Conclusion}

We can conclude from our study that malnutrition is surprisingly at high levels in Madinah. Serious efforts are required jointly by Ministry of Health (MOH), Ministry of Education (MOE) in collaboration with other relevant governmental agencies and Nutrition healthcare professional bodies in order to tackle the unhealthy food environment in the Holy city of Madinah Al Munawarrah.

We greatly acknowledge and highly appreciate the support and encouragement provided by Mr. Mansour Al Askar-Executive Director Prince Muhammad Bin Abdulaziz Hospital, Madinah Al Munawarah-MNGHA. We also acknowledge our Clinical Dietitians at Prince Muhammad Bin Abdulaziz Hospital- Madinah $\mathrm{Al} \mathrm{Mu-}$ nawarah, Ms. Bushra Alharthi, Ms. Nur Adila and Ms. Marwa Al Qarras and all those interns from Taiba University who played a role in the collection of data along with the author and co-authors of this study. We also acknowledge the help extended by Nursing staff namely Mr. Ehab, Kuhail Khldon Hassan, Eyad Numan, Haitham sarhan in data collection. Special thanks for Ms. Eshraq Al oufi for all her secretarial support during proposal writing and data entry and amalgamation. Bundle of thanks go to the Ministry of Education and their dedicated staff, school administration, teachers, students and their parents in Madinah region for their full cooperation. Last but not least King Abdullah International Medical research Centre for their supervision extensive guidance, technical support provided by Institutional Review Board (IRB) and research funding Committee (RFC) for financial support to conduct the study as per GCP/ICH standards.

\section{Bibliography}

1. The Global Syndemic of Obesity, Undernutrition, and Climate Change: The Lancet Commission report www.thelancet.com 393 (2019).

2. World Health Organization. "Children: reducing mortality" (2016).

3. UNICEF, WHO, World Bank Group. Levels and trends in child malnutrition: UNICEF/ WHO/World Bank Group joint child malnutrition estimates (2016).

4. World Health Organization, UNICEF, World Food Programme. "Global nutrition targets 2025: Wasting policy brief" (2014).

5. World Obesity Foundation (2019).
6. Barlow SE. "Expert Committee. Recommendations regarding the prevention, assessment, and treatment of child and adolescent overweight and obesity: Summary report". Pediatrics 120 (2007): S164-192.

7. Centers for Disease Control and Prevention, National Center for Health Statistics (2000).

8. Pediatric Nutrition (Page:50 section E.Body Mass Index) Published by ASPEN (2002).

9. Ministry of Health and Family Welfare India. Participant Manual: Facility based care of severe acute malnutrition (2013).

10. Jonsson U. "Ethics and child nutrition". Food and Nutrition Bulletin 15 (1995): 293-298.

11. Musaiger A. "Overweight and obesity in eastern mediterranean region: prevalence and possible causes". Journal of Obesity (2011): 407237.

12. The Keystone Center. "The Keystone Forum on Away-FromHome Foods: Opportunities for Preventing Weight Gain and Obesity". Washington, DC: The Keystone Center (2006).

\section{Assets from publication with us}

- Prompt Acknowledgement after receiving the article

- Thorough Double blinded peer review

- Rapid Publication

- Issue of Publication Certificate

- High visibility of your Published work

Website: www.actascientific.com/

Submit Article: www.actascientific.com/submission.php Email us: editor@actascientific.com

Contact us: +919182824667 